\title{
Transbronchial biopsy as a tool to evaluate small-airways disease in asthma. Cons
}

\author{
A. James*, N. Carroll ${ }^{\#}$
}

Recently, there has been renewed interest in the importance of the small airways (internal perimeter $<6 \mathrm{~mm}$ ) in asthma [1]. This was initiated largely by the observation that the use of the inhaled corticosteroid beclomethasone as a small-particle formulation, with greater penetration to the peripheral lung, results in similar improvements in symptoms and lung function at half the delivered dose of standard formulations of beclomethasone [2]. The structure of the small airways is altered in asthma, even in mild cases [3], and structural changes in the small airways will theoretically lead to greater alterations in airway mechanics than similar changes in the central airways [4]. Therefore, it seems desirable to find a way to safely assess the pathology of small airways in asthma. Transbronchial biopsy (TBB) is not the way to do it, at least not yet.

In this issue of the Journal, BALzAR et al. [5] have shown that small airways are present in $45 \%$ of TBB specimens from patients with severe asthma. In the same cases, the density (cells $\cdot \mathrm{mm}^{-2}$ ) of inflammatory cells in the small airways (membranous bronchioles and smaller) seen in TBB was greater than the density in endoscopic bronchoscopic biopsies (EBB) from medium and large airways (cartilaginous bronchi) of patients with severe asthma. The authors conclude that TBB may be used to assess pathological changes in small airways in asthma. They have shown considerable endeavour in highlighting the potential of these tissue specimens for study. However, TBB should not yet be regarded as a useful tool for assessing asthma, for two reasons: 1) the significance of greater numbers of inflammatory cells $\cdot \mathrm{mm}^{-2}$ in the distal airway compared with central airways as a marker of a pathological process needs to be validated; and 2) the usefulness of the results does not outweigh the risks involved in obtaining them.

\section{Pathology}

As seen in the study by BALzAR et al. [5], the significance of increased density of inflammatory cells

\footnotetext{
*Dept of Pulmonary Physiology, Sir Charles Gairdner Hospital, Hospital Avenue, Nedlands, and "Surf Science and Technology, Faculty of Regional Professional Studies, Edith Cowan University, Robertson Drive, Bunbury, Western Australia.

Correspondence: A. James, Dept of Pulmonary Physiology, Sir Charles Gairdner Hospital, Hospital Avenue, Nedlands 6009, Western Australia. Fax: 61 893462034. E-mail: ajames@cygnus. uwa.edu.au
}

in the small airways is unclear. The distribution of inflammatory cells in the lung varies with different compartments. The distribution of inflammatory cells across the airway wall varies, even at a given level in the bronchial tree. HALEY et al. [6] demonstrated that the density of inflammatory cells was different from the inner and outer walls of conducting airways. The present authors' own studies have shown that the density of mast cells is greatest on airway smooth muscle and mucous glands and that neutrophil density is greater on mucous glands [7]. There are conflicting results regarding the relative density of inflammatory cells within the airway wall in large and small airways in nonasthmatic and asthmatic subjects, possibly due to differences in methodology and the particular cell type examined. Haley et al. [6] found that the densities of both lymphocytes and eosinophils were greater in central airways than in peripheral airways in patients with asthma and cystic fibrosis. HAMID et al. [8] found little difference in cell density between membranous bronchioles both less than and greater than $2 \mathrm{~mm}$ in diameter with regard to eosinophils, lymphocytes and mast cells. KRAFT [1] demonstrated surprisingly similar findings when comparing EBB and TBB. Wenzel et al. [9] showed an increase in macrophages in TBB compared with EBB in both mild and severe cases of asthma, which contrasts with the findings of FAuL et al. [10]. In their studies of post mortem cases of severe and mild asthma [11], the present authors found that the number of lymphocytes, expressed as cells $\cdot \mathrm{mm}$ of internal perimeter ${ }^{-1}$, was reduced in airways with perimeters $<6 \mathrm{~mm}$, compared with airways $>6 \mathrm{~mm}$ in perimeter. There was little difference between large and small airways for eosinophils, except in the severe cases where greater numbers were seen in the central airways. When the distribution of mast cells in large and small airways was examined [12], it was found that the density was much greater in the peripheral airways, in both asthmatic and nonasthmatic groups. Interestingly, these differences were observed regardless of how the number of mast cells were expressed $\left(\right.$ cells $\cdot \mathrm{mm}$ perimeter ${ }^{-1}$ or cells $\cdot \mathrm{mm}^{-2}$ ), and there were no consistent differences between the asthmatic and nonasthmatic groups with regard to total numbers of mast cells. Findings from these studies suggest that the distribution of inflammatory cells between the large and small airways may differ for lymphocytes, macrophages, eosinophils and mast cells. In the study by BALZAR et al. [5], all inflammatory cells 
were included in the estimation of cell density, although the authors state that monocytes were greater in density in the peripheral lung. The relevance of the increased density of inflammatory cells in the distal airways requires the use of control (nonasthmatic, nonsmokers) tissues.

Estimates of the density of cells in biopsy tissues have largely been undertaken using nonstereological methods, counting cell profiles in two-dimensional thin sections. The degree to which this results in a biased count is unknown but is currently the subject of intense debate. The size of cells relative to section thickness, the orientation of sections, the randomness of the tissue sample and the orientation of cells within the section are all important in accurately determining the true number of cells within a volume of tissue. It can be argued that the relative size and orientation of cells within similar tissues (similar airway sizes) of asthmatics and nonasthmatics is unlikely to be different enough to affect cell count. This argument is less strong, however, when comparing central (large) and peripheral (small) airway tissues. The structure of the airway walls in relation to the relative amounts of connective tissue, blood vessel and smooth muscle is very different in membranous and cartilaginous airways. For example, there is a systematic increase in the relative amount of the total airway cross-section that is occupied by the airway wall as one moves towards distal airways, in both asthmatic and normal lungs $[3,13]$. The relative contributions of the bronchial and pulmonary circulations to airway wall perfusion are different in large and small airways and therefore trafficking of inflammatory cells may be very different in central and peripheral airways. Given these considerations, it is clearly too early to suggest that the number of inflammatory cells in the peripheral airways, compared with central airways, can be used to assess an inflammatory pathological process.

\section{Safety aspects}

Any potential benefits of TBB must be weighed against the potential risks. There is a definite morbidity and mortality associated with TBB. In the study by BALZAR et al. [5], one case of pneumothorax after 90 procedures was reported, and was resolved with conservative management. In 1997, HERF et al. [14] undertook a questionnaire survey of US physicians. They had a $54 \%$ response rate and calculated that the mortality rate associated with transbronchial lung biopsy was $0.2 \%$. Bleeding occurred in $1.3 \%$ and pneumothorax in 5.5\% of procedures. A survey of bronchoscopic practice amongst British physicians in 1986 [15] showed an overall mortality rate of $0.04 \%$ and an incidence of major complications of $0.12 \%$. TBB was associated with an increased mortality rate of $0.12 \%$ and an increased major complication (bleeding and pneumothorax) rate of $2.7 \%$. Other series have shown a pneumothorax rate of $1-4 \%$ and a "significant" haemorrhage rate of $1-8 \%$, with complication rates increased in patients with human immunodeficiency virus (HIV) [16], those in intensive care units [17] and patients who have undergone lung transplantation [18]. While the risk of significant complications is small, this risk is justified only where there is some potential benefit to patients. The results must, therefore, be beneficial.

Testing of the function of small airways remains elusive. Although a number of tests are available that can detect abnormalities of small airways, in the presence of simultaneous disease in the central airways, these tests are not specific. The pathological changes in the airways of patients with asthma involve both the central and peripheral airways and abnormalities of the structure and function of large airways in asthma are likely to confound tests of small-airways disease. The role of imaging techniques has also been examined for their usefulness in assessing small airways. Conventional and newer computed tomography scanners provide quantifiable views of larger airways yet still lack the resolution to adequately examine airways $<1 \mathrm{~cm}$ in diameter. Techniques comparing inspiratory and expiratory computed tomography scans of the lung parenchyma and magnetic resonance imaging with hyperpolarised helium to assess the distribution of ventilation [19] are also being examined but may yet be confounded by the simultaneous presence of pathology in the large and small airways. This adds to the importance of trying to find a method to assess the small airways. While the study by BALZAR et al. [5] shows that small airways can be seen in transbronchial biopsy specimens, the usefulness of the data collected in this way is yet to be defined. The studies of small-particle formulations raise the intriguing possibility that targeting treatment to the small airways may lead to improved outcomes in asthma. This has yet to be proven and the temptation to suggest that transbronchial biopsy might be useful to identify patients who require "targeted" treatment must be resisted until more control data are available.

\section{References}

1. Kraft M. The distal airways: are they important in asthma? Eur Respir J 1999; 14: 1403-1417.

2. Vanden Burgt JA, Busse WW, Martin RJ, Szefler SJ, Donnell D. Efficacy and safety overview of a new inhaled corticosteroid, QVAR (hydrofluoroalkanebeclomethasone extrafine inhalation aerosol), in asthma. J Allergy Clin Immunol 2000; 106: 1209-1226.

3. Carroll NG, Elliot J, Morton AR, James AL. The structure of large and small airways in nonfatal and fatal asthma. Am Rev Respir Dis 1993; 147: 405-410.

4. Wiggs B, Moreno R, James A, Hogg JC, Pare P. A model of the mechanics of airway narrowing in asthma. In: Kaliner MA, Barnes PJ, Persson CGA, eds. Asthma: its pathology and treatment. New York, Marcel Dekker Inc., 1991, pp.74-98.

5. Balzar S, Wenzel SE, Chu HW. Transbronchial biopsy as a tool to evaluate small airways in asthma. Eur Respir J 2002; 20: 254-259.

6. Haley KJ, Sunday ME, Wiggs BR, et al. Inflammatory cell distribution within and along asthmatic airways. Am J Respir Crit Care Med 1998; 158: 565-572.

7. Carroll NG, Mutavdzic S, James AL. Increased mast 
cells and neutrophils in submucosal mucous glands and mucous plugging in patients with asthma. Thorax 2002 (in press).

8. Hamid Q, Song Y, Kotsimbos TC, et al. Inflammation of small airways in asthma. J Allergy Clin Immunol 1997; 100: 44-51.

9. Wenzel SE, Szefler SJ, Leung DYM, Sloan SI, Rex MD, Martin RJ. Bronchoscopic evaluation of severe asthma: Persistent inflammation associated with high dose glucocorticoids. Am J Respir Crit Care Med 1997; 156: 737-743.

10. Faul JL, Tormey VJ, Leonard C, et al. Lung immunopathology in cases of sudden asthma death. Eur Respir J 1997; 10: 301-307.

11. Carroll NG, Cooke C, James AL. The distribution of eosinophils and lymphocytes in the large and small airways of asthmatics. Eur Respir J 1997; 10: 292-300.

12. Carroll NG, Mutavdzic S, James AL. Distribution and degranulation of mast cell in normal and asthmatic subjects. Eur Respir J 2002 (in press).

13. James AL, Pare PD, Hogg JC. The mechanics of airway narrowing in asthma. Am Rev Respir Dis 1989; 139: 242-246.
14. Herf SM, Suratt PM, Arora NS. Deaths and complications associated with transbronchial biopsy. Am Rev Respir Dis 1977; 115: 708-711.

15. Simpson FG, Arnold AG, Purvis A, Belfield PW, Nuers MF, Cooke NJ. Postal survey of bronchoscopic practice by physicians in the United Kingdom. Thorax 1986; 41: 311-317.

16. Steiner S, Schwalen A, Klein RM, et al. Results and complications of fibre bronchonscopy in HIV positive patients. Pneumologie 1998; 52: 694-699.

17. O'Brien JD, Ettinger NA, Shevlin D, Kollef MH. Safety and yield of transbronchial biopsy in mechanically ventilated patients. Crit Care Med 1997; 25: 440446.

18. Diette GB, Wiener CM, White P Jr. The higher risk of bleeding in lung transplant receipients from bronchoscopy is independent of traditional bleeding risks: results of a prospective cohort study. Chest 1999; 115: 397-402.

19. Guenther D, Hanisch G, Kauczor HU. Functional MR imaging of pulmonary ventilation using hyperpolarised noble gases. Acta Radiol 2000; 41: 519528. 